\title{
Development of an automated closed-loop $\beta$-blocker delivery system to stably reduce myocardial oxygen consumption without inducing circulatory collapse in a canine heart failure model: a proof of concept study
}

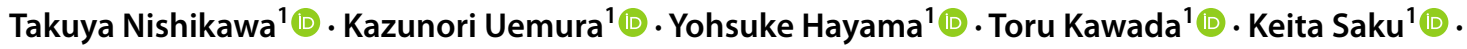 \\ Masaru Sugimachi ${ }^{1}$
}

Received: 22 February 2021 / Accepted: 3 May 2021 / Published online: 10 May 2021

(c) The Author(s) 2021

\begin{abstract}
Beta-blockers are well known to reduce myocardial oxygen consumption $\left(\mathrm{MVO}_{2}\right)$ and improve the prognosis of heart failure (HF) patients. However, its negative chronotropic and inotropic effects limit their use in the acute phase of HF due to the risk of circulatory collapse. In this study, as a first step for a safe $\beta$-blocker administration strategy, we aimed to develop and evaluate the feasibility of an automated $\beta$-blocker administration system. We developed a system to monitor arterial pressure (AP), left atrial pressure $\left(\mathrm{P}_{\mathrm{LA}}\right)$, right atrial pressure, and cardiac output. Using negative feedback of hemodynamics, the system controls AP and $\mathrm{P}_{\mathrm{LA}}$ by administering landiolol (an ultra-short-acting $\beta$-blocker), dextran, and furosemide. We applied the system for $60 \mathrm{~min}$ to 6 mongrel dogs with rapid pacing-induced HF. In all dogs, the system automatically adjusted the doses of the drugs. Mean AP and mean $\mathrm{P}_{\mathrm{LA}}$ were controlled within the acceptable ranges (AP within $5 \mathrm{mmHg}$ below target; $\mathrm{P}_{\mathrm{LA}}$ within $2 \mathrm{mmHg}$ above target) more than $95 \%$ of the time. Median absolute performance error was small for AP [median (interquartile range), 3.1\% (2.2-3.8)] and $\mathrm{P}_{\mathrm{LA}}$ [3.6\% (2.2-5.7)]. The system decreased $\mathrm{MVO}_{2}$ and $\mathrm{P}_{\mathrm{LA}}$ significantly. We demonstrated the feasibility of an automated $\beta$-blocker administration system in a canine model of acute HF. The system controlled $\mathrm{AP}$ and $\mathrm{P}_{\mathrm{LA}}$ to avoid circulatory collapse, and reduced $\mathrm{MVO}_{2}$ significantly. As the system can help the management of patients with $\mathrm{HF}$, further validations in larger samples and development for clinical applications are warranted.
\end{abstract}

Keywords Beta-blocker $\cdot$ Automated drug delivery $\cdot$ Closed-loop control $\cdot$ Hemodynamics

\section{Introduction}

Beta-blockers are drugs that bind to beta-adrenergic receptors and inhibit the binding of norepinephrine and epinephrine [1]. This inhibition reduces the cardiac workload and myocardial oxygen consumption $\left(\mathrm{MVO}_{2}\right)$ through negative chronotropic and inotropic effects [2,3]. This is the key mechanism of cardioprotection by $\beta$-blockers. Other mechanisms of cardioprotection by $\beta$-blockers include the suppression of renin release [4], reduction of myocardial

Takuya Nishikawa

nishikawa.takuya75@ncvc.go.jp

1 Department of Cardiovascular Dynamics, National Cerebral and Cardiovascular Center Research Institute, Kishibe-Shinmachi 6-1, Suita, Japan oxygen stress [5], and normalisation of calcium handling in the sarcoplasmic reticulum [6].

In the chronic phase of heart failure (HF), it is well known that $\beta$-blockers reduce cardiac remodelling and improve the prognosis of HF patients with reduced ejection fraction [7, 8]. In the acute phase, perioperative stress increases norepinephrine and epinephrine spillover [9] causing tachycardia and hypertension, and increases $\mathrm{MVO}_{2}$ [10]. Excessive $\mathrm{MVO}_{2}$ leads to myocardial ischemia. The European guideline recommends using $\beta$-blockers in the perioperative phase of cardiac surgery [11]. In addition, withdrawal of $\beta$-blockers in the acute phase of acute decompensated HF worsens the prognosis [12]. These studies indicate the benefit of $\beta$-blockers in acute phase. However, in patients with impaired cardiac function, the negative inotropic and chronotropic effects of $\beta$-blockers may lead to circulatory collapse, i.e., cardiogenic shock or pulmonary congestion 
[13-15]. This risk of circulatory collapse hampers the use of $\beta$-blockers in high-risk patients. A safe method of $\beta$-blocker administration will permit the use of $\beta$-blockers in high-risk patients and may provide cardioprotective effects. Since the range of dosage adjustment is narrow in high-risk patients, we hypothesized that automated drug regulation based on negative feedback of hemodynamics can control the dosage of $\beta$-blocker appropriately. We previously developed automated cardiovascular drug delivery systems that administered inotropic agents, vasodilators, diuretics, and/or infused fluids to simultaneously control arterial pressure (AP), cardiac output $(\mathrm{CO})$, and left atrial pressure $\left(\mathrm{P}_{\mathrm{LA}}\right)$ under acute HF condition [16-18]. We hypothesize that by allowing a mild drop of AP to an acceptable range, we can extend the system to handle the infusion of $\beta$-blockers in acute HF. Jannet et al. [19] reported an automated drug delivery system for $\beta$-blockers, which controlled heart rate (HR) by administering esmolol, a short-acting $\beta$-blocker. However, since they focused on HR only, the risk of esmolol-induced circulatory collapse remained unsolved.

With this background, we believe that a safe $\beta$-blocker administration strategy will provide cardioprotective effects and be useful in the management of patients with acute HF. As a first step for the strategy, we developed an automated $\beta$-blocker administration system that administered landiolol, an ultra-short-acting $\beta$-blocker, using negative feedback control of hemodynamics. The aim of this study is to prove the concept of our proposed system and to evaluate the feasibility of the system in a canine model of HF.

\section{Methods}

\subsection{Automated drug delivery system}

In this study, by extending the systems that we reported previously [16-18], we developed an automated drug delivery system to control the infusion rates of landiolol and dextran, and the injection of furosemide to reduce $\mathrm{MVO}_{2}$ without inducing circulatory collapse in subjects with acute HF. Figure 1a shows the scheme of our system. The details of the system are described in Supplemental material. In brief, the user sets the target values of mean $\mathrm{AP}\left(\mathrm{AP}^{*}\right)$ and mean $\mathrm{P}_{\mathrm{LA}}\left(\mathrm{P}_{\mathrm{LA}}{ }^{*}\right)$. The system measures $\mathrm{AP}, \mathrm{CO}, \mathrm{P}_{\mathrm{LA}}$ and right atrial pressure $\left(\mathrm{P}_{\mathrm{RA}}\right)$. From the measured hemodynamic variables, the system calculates the slope of the Frank-Starling curve for left $\left(S_{L}\right)$ and right $\left(S_{R}\right)$ ventricles, systemic vascular resistance $(\mathrm{R})$ and stressed blood volume (V) (Fig. 1b top panel). From $\mathrm{AP}^{*}$ and $\mathrm{P}_{\mathrm{LA}}{ }^{*}$, and the measured hemodynamic data, the system determines the target values of $\mathrm{S}_{\mathrm{L}}$ $\left(\mathrm{S}_{\mathrm{L}}{ }^{*}\right)$ and $\mathrm{V}\left(\mathrm{V}^{*}\right)$ from $\mathrm{AP}^{*}$ and $\mathrm{P}_{\mathrm{LA}}{ }^{*}$, and calculates hemodynamic parameters (Fig. 1b bottom panel). To minimise the difference between $\mathrm{S}_{\mathrm{L}}{ }^{*}$ and $\mathrm{S}_{\mathrm{L}}\left(\Delta \mathrm{S}_{\mathrm{L}}\right)$, a proportional-integral feedback controller adjusts the infusion rate of landiolol (Fig. 1c top panel). To minimise the difference between $\mathrm{V}^{*}$ and $\mathrm{V}(\Delta \mathrm{V})$, a nonlinear feedback controller adjusts the infusion rate of dextran or the injection of furosemide (Fig. 1c bottom panel). Using these feedback controllers, the system administers landiolol and dextran or furosemide to bring mean $\mathrm{AP}$ and mean $\mathrm{P}_{\mathrm{LA}}$ to the preset target values.

\subsection{Animal experiments}

\subsubsection{Rapid pacing-induced heart failure model}

We used six adult mongrel dogs weighing $21.0-29.5 \mathrm{~kg}$ (male/female, 4/2). We induced anaesthesia with intravenous thiamylal sodium $\left(25 \mathrm{mg} \mathrm{kg}^{-1}\right)$, performed endotracheal intubation, and maintained an appropriate anaesthesia level during the experiment by continuous inhalation of isoflurane $(1-2 \%)$ under mechanical ventilation. Body temperature was maintained between 37 and $38^{\circ} \mathrm{C}$. We performed transthoracic echocardiography to measure left ventricular end-diastolic dimension (LVDD), left ventricular end-systolic dimension (LVDS) and ejection fraction under normal conditions. After inserting a bipolar pacing lead (Model BT-60P, Star Medical Inc., Tokyo, Japan) to the right ventricular apex through the right jugular vein, we connected a generator (Model SIP-501, Star Medical, Tokyo, Japan) to the pacing lead and implanted it in a subcutaneous pocket at the neck [17]. We closed the incisions and withdrew anaesthesia. One day after implantation, we started rapid ventricular pacing at a rate of 230 beats. $\mathrm{min}^{-1}$ and continued for three weeks to induce HF.

\subsubsection{Experimental preparation and automated drug control}

We performed experiments the day after discontinuing rapid pacing. Under anaesthesia induced as described above, we performed transthoracic echocardiography to assess LVDS, LVDD and ejection fraction, and recorded an electrocardiogram (ECG) to calculate HR. We placed 8-Fr sheath introducers in the right femoral artery to measure AP, and in the right and left femoral veins for infusing dextran and landiolol, respectively, and placed a 10-Fr sheath introducer in the right jugular vein to measure $\mathrm{P}_{\mathrm{RA}}$. We inserted a catheter to the coronary sinus via the right jugular vein under fluoroscopy. After a left thoracotomy and pericardial incision, we introduced a catheter into the left atrial appendage to measure $\mathrm{P}_{\mathrm{LA}}$. We placed ultrasonic flow probes at the ascending aorta (20PS; Transonic, Ithaca, NY) and the left circumflex artery (2.5PS; Transonic, Ithaca, NY) to measure CO and coronary flow, respectively.

We attached an infusion pump (CFV-3200, Nihon Kohden, Tokyo, Japan) for administering landiolol, and a roller 
a

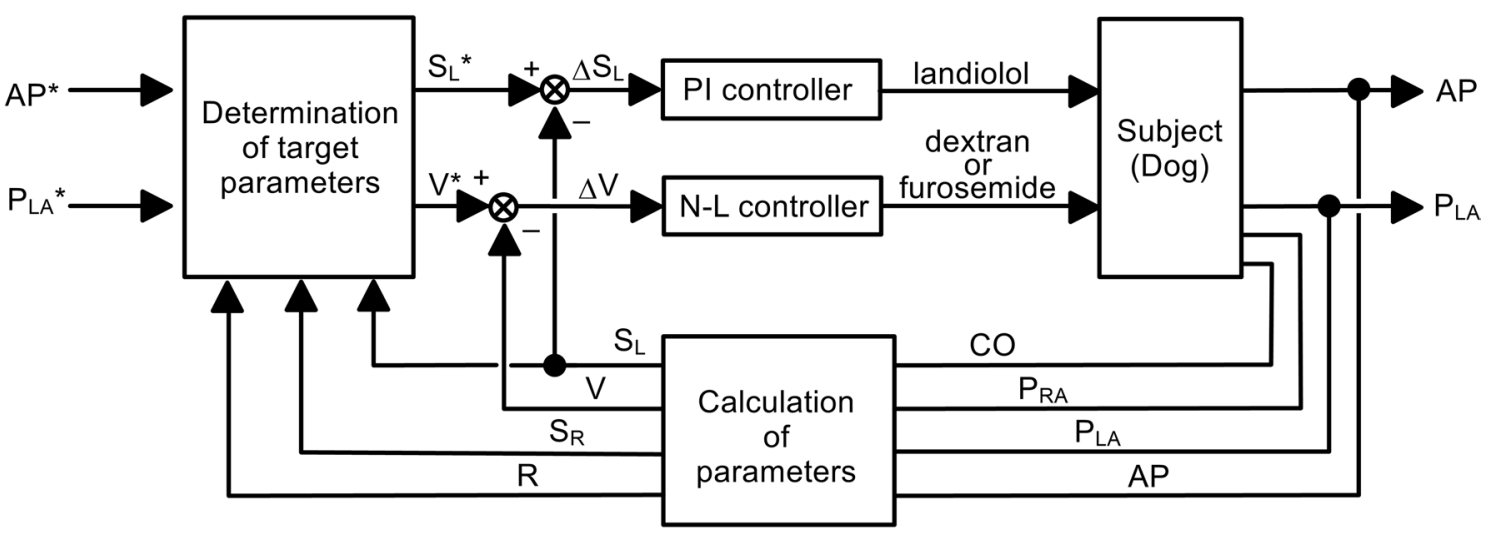

b Calculation of parameters $\left(S_{L}, V, S_{R}, R\right)$

$\mathrm{S}_{\mathrm{L}}=\frac{\mathrm{CO}}{\ln \left(\mathrm{P}_{\mathrm{LA}}-2.03\right)+0.8}$

$V=0.129 \times\left(C O+19.61 \times P_{R A}+3.49 \times P_{L A}\right)$

$\mathrm{S}_{\mathrm{R}}=\frac{\mathrm{CO}}{\ln \left(\mathrm{P}_{\mathrm{RA}}-2.13\right)+1.9}$

$R=\frac{A P-P L A}{C O}$

Determine $S_{L}, V, S_{R}$, and $R$ from measured $C O, P_{L A}, P_{R A}$, and $A P$

Determination of target parameters $\left(S_{L}{ }^{*}, V^{*}\right)$

$\mathrm{AP}^{*}=\mathrm{CO} \mathrm{O}^{*} \times \mathrm{R}+\mathrm{P}_{\mathrm{RA}}{ }^{*}$

$\mathrm{V}^{*}=0.129 \times\left(\mathrm{CO}^{*}+19.61 \times \mathrm{P}_{\mathrm{RA}}{ }^{*}+3.49 \times \mathrm{P}_{\mathrm{LA}}{ }^{*}\right)$

$\mathrm{CO}^{*}=\mathrm{S}_{\mathrm{L}}{ }^{*} \times\left(\ln \left(\mathrm{P}_{\mathrm{LA}}{ }^{*}-2.03\right)+0.8\right)$

$C O^{*}=S_{R}{ }^{*} \times\left(\ln \left(P_{R A^{*}}-2.13\right)+1.9\right)$

$\frac{S_{L}^{*}}{S_{R}^{*}}=\frac{S_{L}}{S_{R}}$

Determine $S_{L}{ }^{*}, V^{*}, S_{R}{ }^{*}, C O^{*}$ and $P_{R A}{ }^{*}$ from $A P^{*}, P_{L A}{ }^{*}, S_{L}, S_{R}$, and $R$ and use $\mathrm{S}_{\mathrm{L}^{*}}$ and $\mathrm{V}^{*}$ for hemodynamic control

Fig. 1 a Schematic representation of the automated drug delivery system to control arterial pressure (AP) and left atrial pressure $\left(\mathrm{P}_{\mathrm{LA}}\right)$. From measured AP, $\mathrm{P}_{\mathrm{LA}}$, right atrial pressure $\left(\mathrm{P}_{\mathrm{RA}}\right)$ and cardiac output $(\mathrm{CO})$, the system calculates hemodynamic parameters comprising $S_{L}$ (slope of Frank-Starling curve for left ventricle), $S_{R}$ (slope of Frank-Starling curve for right ventricle), stressed blood volume (V) and systemic vascular resistance $(\mathrm{R})$. From $\mathrm{S}_{\mathrm{R}}, \mathrm{R}$, target AP (AP*) and target $\mathrm{P}_{\mathrm{LA}}\left(\mathrm{P}_{\mathrm{LA}}{ }^{*}\right)$, the system determines target $\mathrm{S}_{\mathrm{L}}\left(\mathrm{S}_{\mathrm{L}}{ }^{*}\right)$ and $\mathrm{V}$ $\left(\mathrm{V}^{*}\right)$. The infusion rate of landiolol is controlled by a proportional-

pump (Minipulse 3, Gilson, Middleton, WI) for administering dextran. We controlled these pumps via a laboratory computer (LC-72N10, Logitec, Tokyo, Japan). We used the sheath introducer at the femoral vein for injecting furosemide according to a command signal from the computer. We digitised all hemodynamic data at $200 \mathrm{~Hz}$ with an analogue-to-digital converter (AD 12-16, Contec, Osaka, Japan) and stored the data in a dedicated laboratory computer system.
C

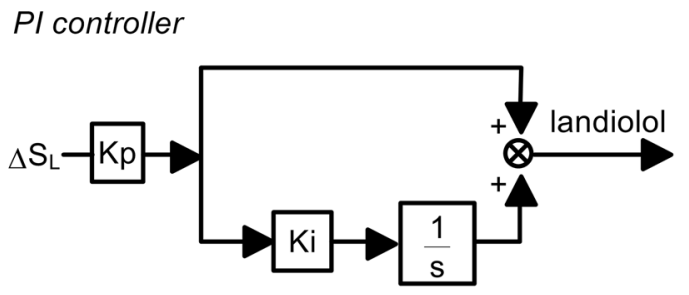

$N-L$ controller

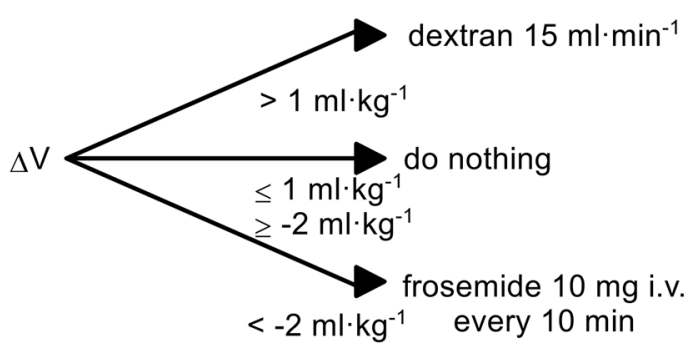

integral (PI) controller to minimise the difference between $\mathrm{S}_{\mathrm{L}}{ }^{*}$ and $\mathrm{S}_{\mathrm{L}}$ $\left(\Delta \mathrm{S}_{\mathrm{L}}\right)$. The infusion rate of dextran and injection of furosemide are controlled by a nonlinear (N-L) controller to minimise the difference between $\mathrm{V}^{*}$ and $\mathrm{V}(\Delta \mathrm{V})$. By controlling $\mathrm{S}_{\mathrm{L}}$ and $\mathrm{V}$, AP and $\mathrm{P}_{\mathrm{LA}}$ reach preset target values. $\mathbf{b}$ Equations used in parameter calculation and determination of target parameters. $\mathrm{P}_{\mathrm{RA}}{ }^{*}$ indicates target $\mathrm{P}_{\mathrm{RA}}$, and $\mathrm{S}_{\mathrm{R}}{ }^{*}$ indicates target $S_{R}$. $c$ Details of the controllers of drugs. Kp, proportional gain; $\mathrm{Ki}$, integral gain. $s$ is a Laplace operator, and $1 / s$ indicates integration

\subsubsection{Experimental protocol}

After stabilisation for $30 \mathrm{~min}$, we connected the closed-loop system to the animal. We set $\mathrm{AP}^{*}$ as $10-15 \mathrm{mmHg}$ lower than baseline AP, but not lower than $70 \mathrm{mmHg}$. We set $\mathrm{P}_{\mathrm{LA}}$ * as baseline $\mathrm{P}_{\mathrm{LA}}$, but not higher than $18 \mathrm{mmHg}$. After activating the system by closing the feedback loops of drug administration (Fig. 1), we recorded the infusion rates of landiolol and dextran and the injection of furosemide on the 
computer. The performance of the system was monitored for $60 \mathrm{~min}$, and arterial and coronary sinus blood samples were collected simultaneously at baseline ( $0 \mathrm{~min}), 30$, and $60 \mathrm{~min}$ after system activation.

After completion of the protocol, the dogs were euthanized with an intravenous injection of pentobarbital and potassium chloride. We measured left ventricular weight after excising the adjacent right ventricular muscle and valvular tissues.

\subsubsection{Myocardial oxygen consumption and blood gas analysis}

We measured oxygen contents of the arterial and coronary sinus blood samples using a co-oximeter (AVOXimeter 4000; Instrumentation Laboratory, Bedford, MA). According to Fick's principle, the product of coronary flow and the difference between arterial and coronary sinus oxygen contents yields $\mathrm{MVO}_{2}$. We normalized $\mathrm{MVO}_{2}$ by $100 \mathrm{~g}$ left ventricular weight (LVW). We also performed blood gas analysis of arterial blood samples using a blood gas analyser (ABL800 FLEX; Radiometer, Tokyo, Japan) to assess pH, electrolytes, lactate, and partial pressure oxygen and carbon dioxide.

\subsection{Data analysis}

\subsubsection{Performance of the automated drug delivery system.}

We defined the acceptable range for $\mathrm{AP}$ as $\mathrm{AP}^{*}-5 \mathrm{mmHg}$ or above, and for $\mathrm{P}_{\mathrm{LA}}$ as $\mathrm{P}_{\mathrm{LA}}{ }^{*}+2 \mathrm{mmHg}$ or below. We evaluated the percentage of time in which mean AP or mean $\mathrm{P}_{\mathrm{LA}}$ was within the acceptable range. To evaluate the precision and stability of the system, we calculated the performance error (PE), median PE (MDPE), median absolute PE (MDAPE), and wobble by the following equations [20].

$P E(t)=\frac{\text { Variable }(t)-\operatorname{Target}(t)}{\operatorname{Variable}(t)} \times 100$

$\operatorname{MDPE}=\operatorname{median}\{\mathrm{PE}(\mathrm{t})\}$

$\operatorname{MDAPE}=\operatorname{median}\{|\mathrm{PE}(\mathrm{t})|\}$

Wobble $=\operatorname{median}\{|\mathrm{PE}(\mathrm{t})-\mathrm{MDPE}|\}$

where $t$ represents a time unit. Divergence is the slope of the regression line between $|\mathrm{PE}(\mathrm{t})|$ and $\mathrm{t}(\mathrm{min})$. MDPE, MDAPE, wobble, and divergence indicate the bias, accuracy, stability, and trend of the absolute error, respectively. Since hemodynamics was stabilised after approximately $15 \mathrm{~min}$, we calculated $\mathrm{PE}$ for $\mathrm{AP}$ and $\mathrm{P}_{\mathrm{LA}}$ from 15 to $60 \mathrm{~min}$ after the system was activated.

\subsection{Statistics}

Data are expressed as median (interquartile range). We used Wilcoxon signed rank test to compare echocardiographic variables obtained before and after creating the rapid pacinginduced HF model. We performed a post hoc power analysis to assess the effect size and power of the tests. Wilcoxon signed rank test and Friedman's test were performed using $\mathrm{R}$ version 3.4.3 (R Foundation for Statistical Computing, Vienna, Austria). Post hoc power analysis was performed using G*Power Version 3.1.9.6 (Faul et al. 2007). We considered differences to be significant at $p<0.05$.

\section{Results}

\subsection{Rapid pacing-induced heart failure model}

Rapid pacing significantly increased LVDD [before to after 3-week pacing: 42 (40-43) to $53 \mathrm{~mm}(46-53), p<0.05]$ and LVDS [29 (28-31) to $44 \mathrm{~mm}(37-44), p<0.05$ ], and reduced ejection fraction [58 (55-61) to $37 \mathrm{~mm}(35-38), p<0.05$ ] (Fig. 2). Mean AP and mean $\mathrm{P}_{\mathrm{LA}}$ just before activation of the drug delivery system were $87 \mathrm{mmHg}(85-89)$ and $17 \mathrm{mmHg}$ (15-19), respectively. These data indicated that rapid pacing for three weeks induced HF in the animals.

\subsection{Hemodynamic control by the automated drug delivery system}

Figure 3 shows the representative time series data of one dog during hemodynamic control by the system. After activation at $0 \mathrm{~min}$, the system started to control the infusion rates of landiolol and dextran, and injection of furosemide (Fig. 3a). As a result, the hemodynamic parameters $S_{L}$ and $\mathrm{V}$ approached their respective target values (Fig. 3b). By controlling $\mathrm{S}_{\mathrm{L}}$ and $\mathrm{V}$, mean $\mathrm{AP}$ and mean $\mathrm{P}_{\mathrm{LA}}$ reached the preset target values accurately (Fig. 3c). HR and coronary flow were reduced markedly within $20 \mathrm{~min}$ (Fig. 3d). From 15 to 60 min after the system activation, IPEl for mean AP or mean $\mathrm{P}_{\mathrm{LA}}$ was less than $10 \%$.

Figure 4 summarises the results of time series data of all six dogs. The solid line and the grey shade indicate median and interquartile range, respectively. Figure 4a shows the infusion rate of landiolol and cumulative doses of dextran and furosemide. The trend of landiolol infusion rate varied among the animals. In three dogs, the infusion rate of landiolol initially increased, then gradually decreased. In the other three dogs, the infusion rate of landiolol increased gradually over time during hemodynamic control. In all dogs, the infusion rate of landiolol averaged over the 60 -min period was $26.2 \mu \mathrm{g} \mathrm{min}^{-1} \mathrm{~kg}^{-1}$ (11.4-37.9), and the cumulative dose of dextran was $4.1 \mathrm{ml} \mathrm{kg}^{-1}$ (3.7-4.4). Furosemide was injected 
$\operatorname{LVDD}(\mathrm{mm})$

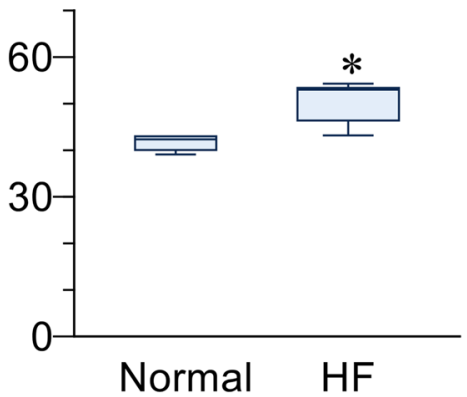

$\operatorname{LVDS}(\mathrm{mm})$

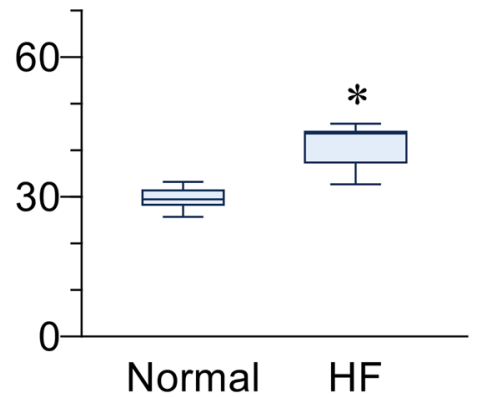

EF $(\%)$

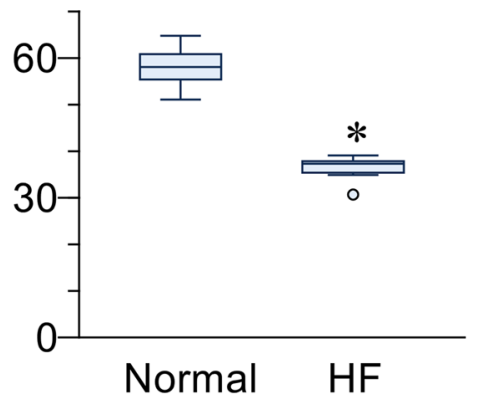

Fig. 2 Echocardiographic variables of cardiac function measured before (Normal) and after three weeks of rapid cardiac pacing to induce heart failure (HF). LVDD, left ventricular end-diastolic dimension; LVDS, left ventricular end-systolic dimension; EF, ejection fraction. $* p<0.05$ vs. normal
A
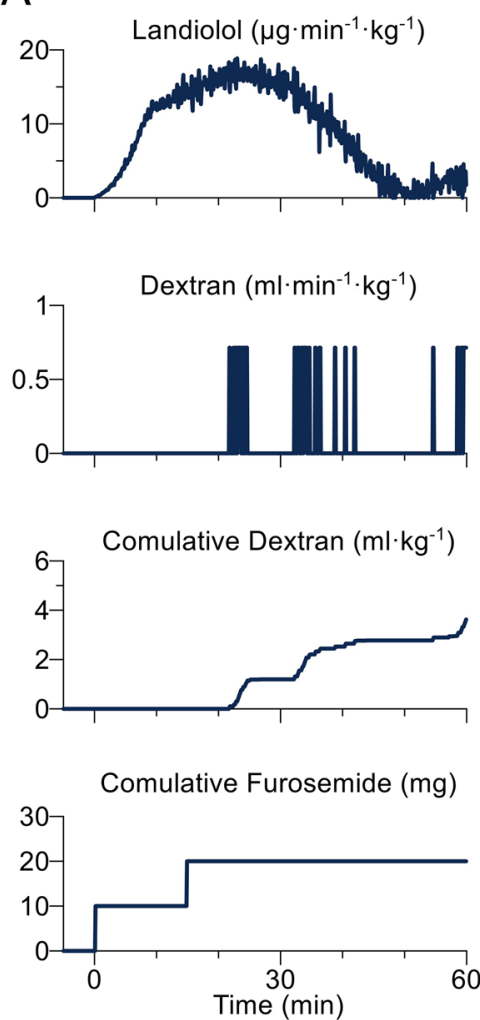

B

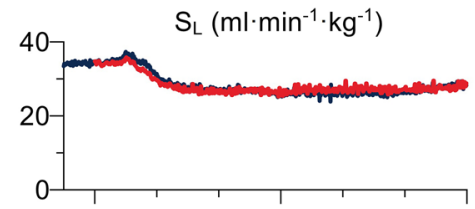

$\mathrm{V}\left(\mathrm{ml} \cdot \mathrm{kg}^{-1}\right)$
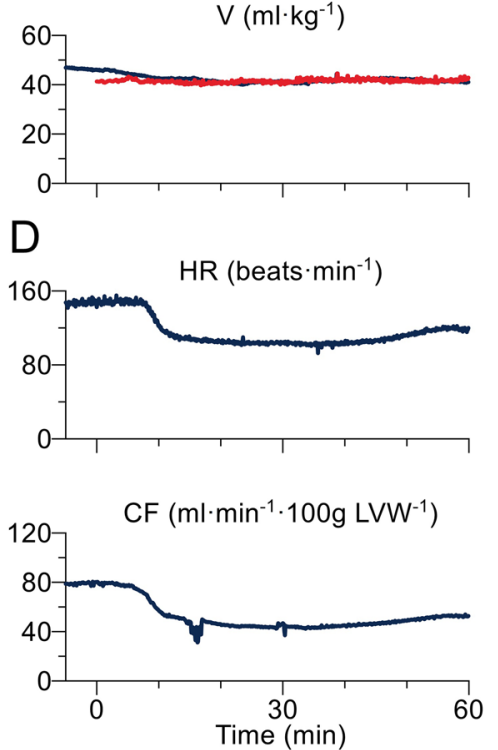

C
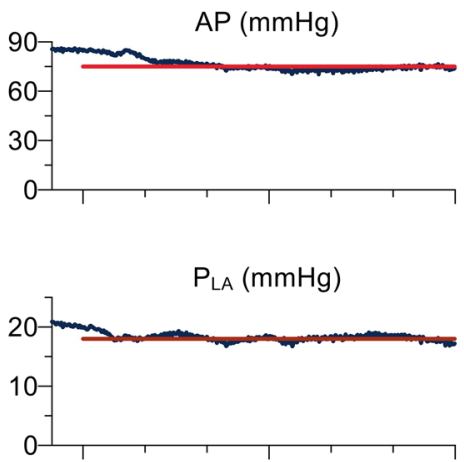

$\mathrm{E}$
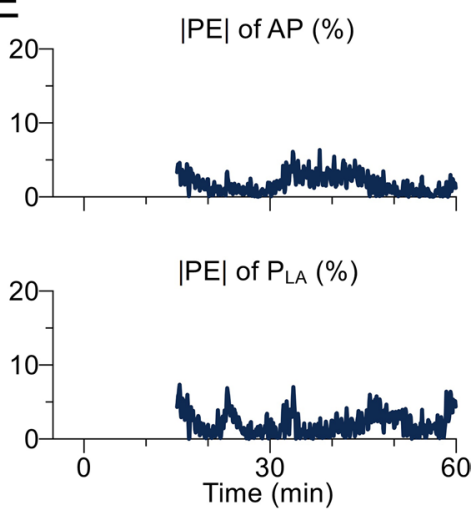

Fig. 3 Representative time series data of one dog during hemodynamic control by the automated drug delivery system. a Infusion rates of landiolol and dextran, and cumulative doses of dextran and furosemide; $\mathbf{b}$ slope of Frank-Starling curve for left ventricle $\left(\mathrm{S}_{\mathrm{L}}\right)$ and stressed blood volume (V); c mean arterial pressure (AP) and mean left atrial pressure $\left(\mathrm{P}_{\mathrm{LA}}\right)$; $\mathbf{d}$ heart rate $(\mathrm{HR})$ and coronary flow $(\mathrm{CF})$; e absolute performance error (IPEI) for AP and $\mathrm{P}_{\mathrm{LA}}$. Navy blue and red lines indicate measured and target values, respectively in three dogs, and the cumulative furosemide dose was 15 mg (2.5-27.5). Figure 4b, c show the errors of $S_{L}, V, A P$, and $\mathrm{P}_{\mathrm{LA}}$. IPEI for mean AP or mean $\mathrm{P}_{\mathrm{LA}}$ was less than $10 \%$ from 15 to $60 \mathrm{~min}$ after system activation (Fig. 4d).

Figure 5 summarises the hemodynamic data and $\mathrm{MVO}_{2}$ at baseline ( $0 \mathrm{~min}), 30$, and $60 \mathrm{~min}$ after system activation.
Mean AP [baseline: 87 (85-89); 30 min: 81 (76-83); 60 min: $77 \mathrm{mmHg}(74-81), p<0.01]$, systolic AP [baseline: 117 (114-120); 30 min: 111 (104-115); $60 \mathrm{~min}: 106 \mathrm{mmHg}$ (101-112), $p<0.01]$ and diastolic AP [baseline: 71 (68-74); 30 min: 66 (64-67); 60 min: $63 \mathrm{mmHg}(61-66), p<0.01]$ decreased significantly at 30 and 60 min compared to 


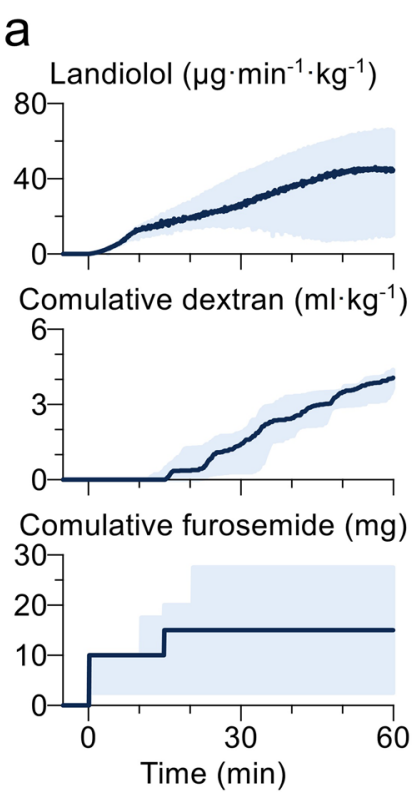

b

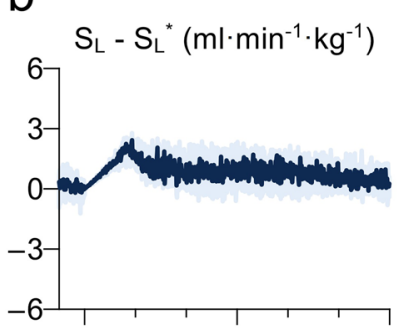

C

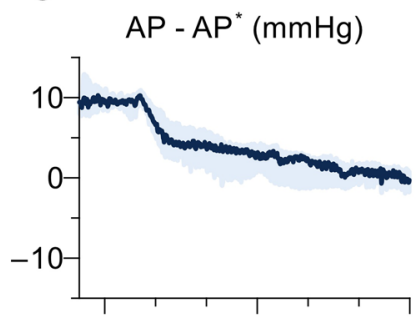

$\mathrm{V}-\mathrm{V}^{*}\left(\mathrm{ml} \cdot \mathrm{kg}^{-1}\right)$
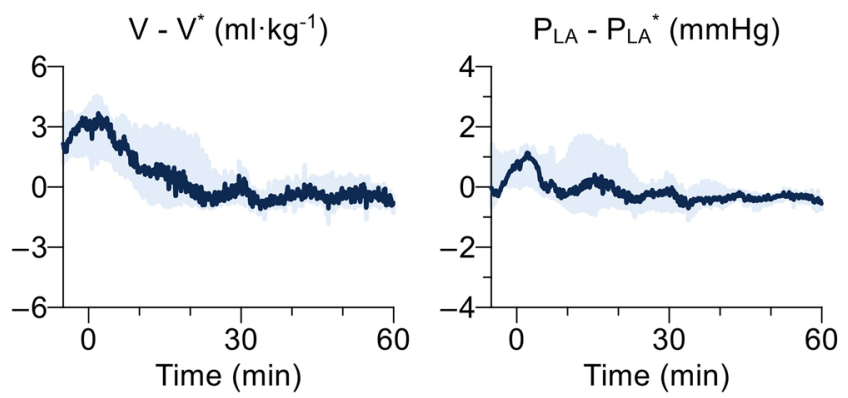

d
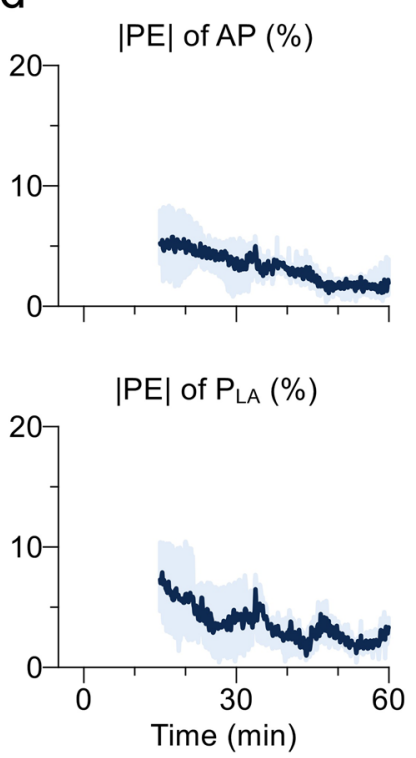

Fig. 4 Summarised time series data of six dogs during hemodynamic control by the automated drug delivery system. Data are expressed as median (solid line) and interquartile range (blue area). a Infusion rates of landiolol and dextran, and cumulative doses of dextran and furosemide; $\mathbf{b}$ difference between measured and target values of slope

baseline. However, in all dogs, the system maintained mean AP not lower than $70 \mathrm{mmHg}$, and systolic AP not lower than $100 \mathrm{mmHg}$ during the 60-min hemodynamic control period. Mean $\mathrm{P}_{\mathrm{LA}}$ was slightly but significantly lower compared to baseline [baseline: 16.7 (15.5-19.0); $30 \mathrm{~min}: 16.2$ (14.4-18.1); $60 \mathrm{~min}: 16.0 \mathrm{mmHg}(14.7-17.2), p<0.05]$, whereas $\mathrm{P}_{\mathrm{RA}}$ remained unaltered [baseline: $9.1(8.1-10.7)$; 30 min: 10.0 (9.1-10.4); 60 min: 10.4 mmHg (9.6-13.4), $p=0.3$. These results indicated that our system prevented cardiogenic shock and/or pulmonary congestion. $\mathrm{MVO}_{2}$ decreased significantly at 30 and 60 min compared to baseline [baseline: 3.8 (3.4-4.0); $30 \mathrm{~min}: 2.9(2.7-3.2)$; $60 \mathrm{~min}$ : $\left.3.0 \mathrm{ml} \mathrm{min}{ }^{-1}(2.6-3.4) \cdot 100 \mathrm{~g} \mathrm{LVW}^{-1}, p<0.01\right]$. HR [baseline: 129 (118-138); 30 min: 106 (104-107); 60 min: 105 bpm (103-111), $p<0.01$ ], CO [baseline: 118 (101-124); 30 min: 86 (75-92); $\left.60 \mathrm{~min}: 84 \mathrm{ml} \mathrm{min} \mathrm{kg}{ }^{-1}(64-95), p<0.01\right]$, and coronary flow [baseline: 68 (59-77); $30 \mathrm{~min}: 51 \mathrm{ml}$ $\min ^{-1}$ (48-66) $\left.100 \mathrm{~g} \mathrm{LVW}^{-1}, p<0.01\right]$ decreased significantly at 30 and 60 min compared to baseline.

\subsection{Performance of the automated system}

Table 1 shows the performance of the automated system. In all dogs, mean AP was controlled within the acceptable range $100 \%$ of the time. Mean $\mathrm{P}_{\mathrm{LA}}$ was controlled within the acceptable range $99.7 \%$ (94-100) of the time. These results indicated that the system did not induce circulatory collapse during almost the entire period of hemodynamic

of Frank-Starling curve for left ventricle $\left(\mathrm{S}_{\mathrm{L}}\right)$ and stressed blood volume $(\mathrm{V})$; c difference between measured and target values of mean arterial pressure (AP) and mean left atrial pressure $\left(\mathrm{P}_{\mathrm{LA}}\right)$; $\mathbf{d}$ absolute performance error $(\mid \mathrm{PEl})$ for $\mathrm{AP}$ and $\mathrm{P}_{\mathrm{LA}}$

control. The MDAPE (\%) for mean AP and mean $\mathrm{P}_{\mathrm{LA}}$ was $3.1(2.2-3.8)$ and 3.6 (2.2-5.7), respectively; MDPE (\%) was $3.1(-0.2-3.7)$ and $-1.8(-3.6$ to -0.04$)$; wobble $(\%)$ was $2.1(1.6-2.5)$ and $2.4(1.1-3.0)$; and divergence $\left(\% \mathrm{~min}^{-1}\right)$ was $-0.09(-0.13$ to -0.02$)$ and $-0.09(-0.17$ to -0.01$)$. These results indicated that the system automatically controlled AP and $\mathrm{P}_{\mathrm{LA}}$.

\subsection{Blood gas analysis}

Table 2 shows the data of blood gas analysis. Despite the significant reduction in $\mathrm{CO}$, lactate remained unaltered. This result suggested that the system maintained peripheral perfusion adequately. All other blood gas parameters did not change significantly during hemodynamic control.

\subsection{Post hoc power analysis}

Table S1 in Supplemental material summarises the results of a post hoc power analysis. Although Friedman's test showed no significant difference in $\mathrm{P}_{\mathrm{RA}}$, stressed blood volume $(\mathrm{V}), \mathrm{pH}$, partial pressure of arterial oxygen $\left(\mathrm{PaO}_{2}\right)$, partial pressure of arterial carbon dioxide $\left(\mathrm{PaCO}_{2}\right)$, bicarbonate $\left(\mathrm{HCO}_{3}{ }^{-}\right)$, base excess $(\mathrm{BE})$, and lactate by hemodynamic control, all these variables showed small $(<0.3)$ effect sizes and low $(<0.8)$ statistical power $(1-\beta)$. 

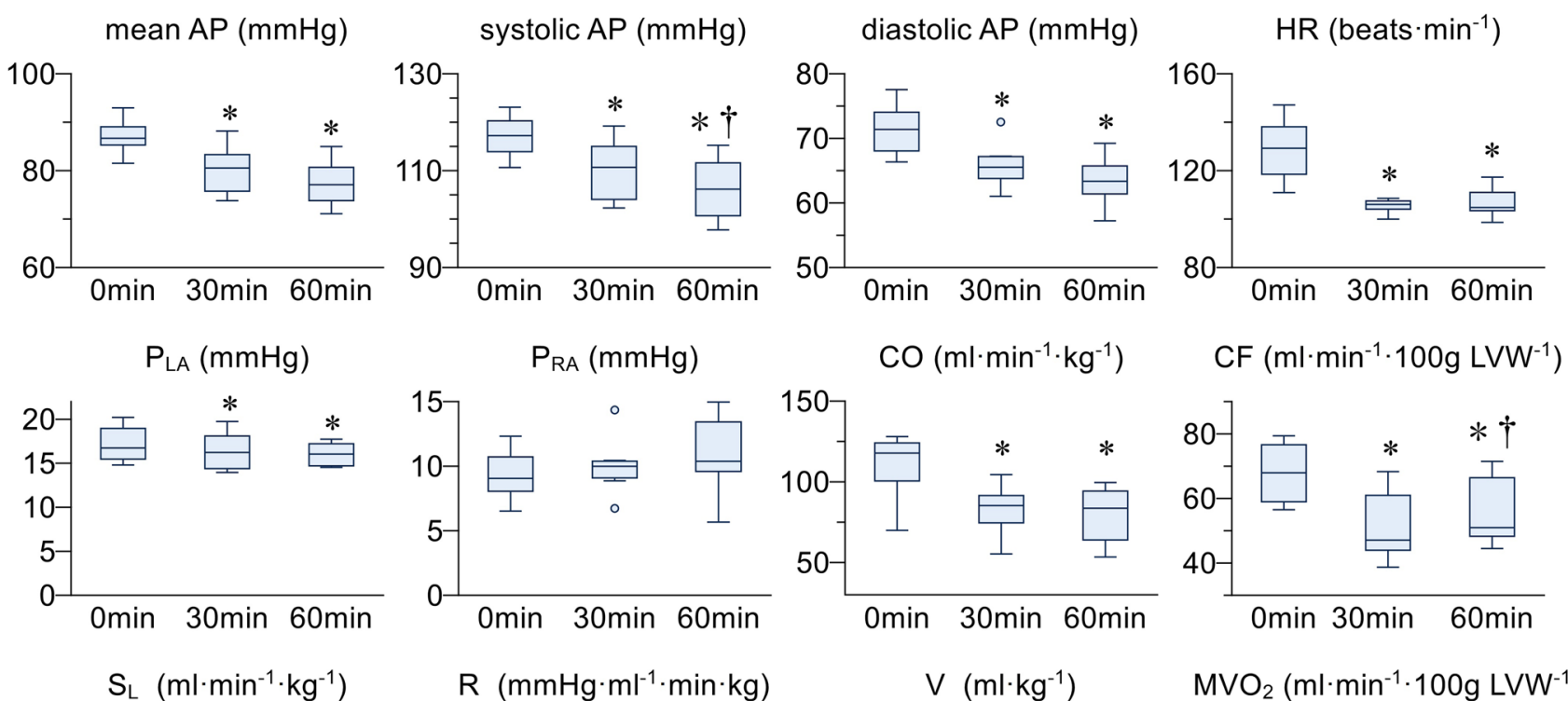

$S_{L}\left(\mathrm{ml} \cdot \mathrm{min}^{-1} \cdot \mathrm{kg}^{-1}\right)$

$\mathrm{R}\left(\mathrm{mmHg} \cdot \mathrm{ml}^{-1} \cdot \mathrm{min} \cdot \mathrm{kg}\right)$
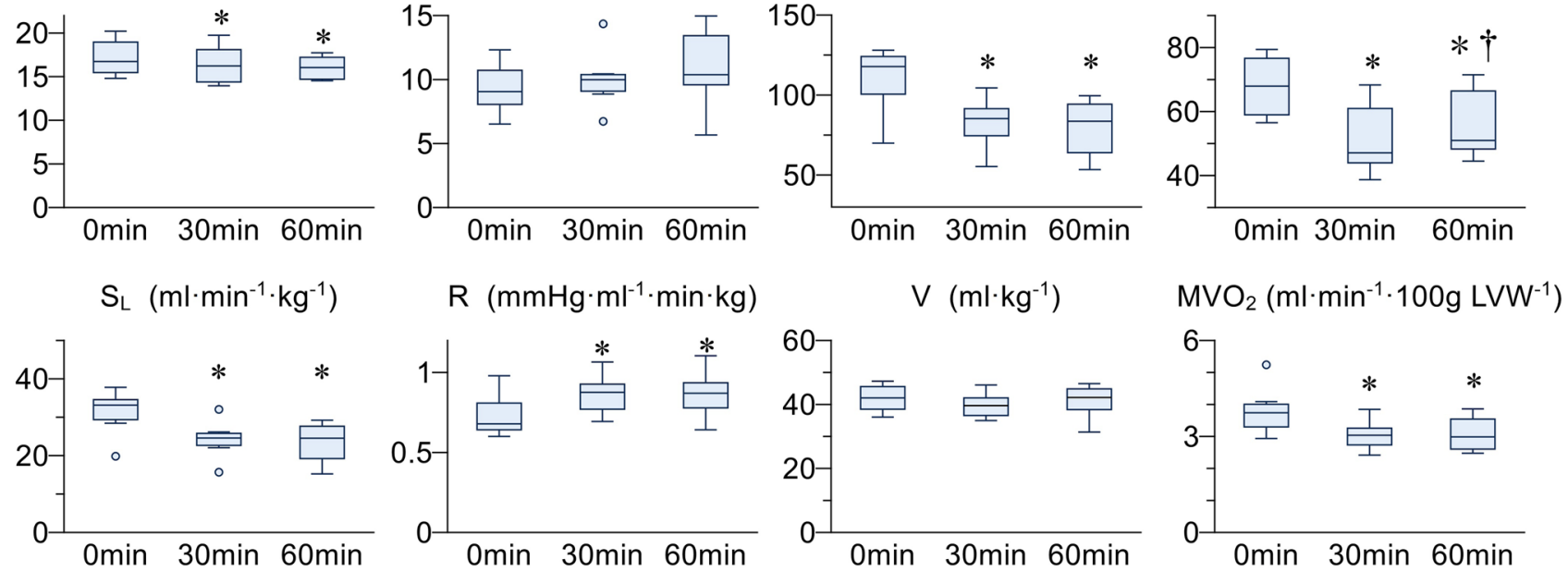

Fig. 5 Summarised hemodynamic and energetics data of six dogs obtained at $0 \mathrm{~min}, 30 \mathrm{~min}$, and $60 \mathrm{~min}$ after the system was activated. Boxes represent median and interquartile range. Whiskers represent minimum and maximum values. Outliers are represented as circles. $\mathrm{AP}$, arterial pressure; $\mathrm{P}_{\mathrm{LA}}$, left atrial pressure; $\mathrm{P}_{\mathrm{RA}}$, right atrial pres-

sure; $\mathrm{HR}$, heart rate; $\mathrm{CO}$, cardiac output; $\mathrm{CF}$, coronary flow; $\mathrm{S}_{\mathrm{L}}$, slope of Frank-Starling curve for left ventricle; R, systemic vascular resistance; $\mathrm{V}$, stressed blood volume; $\mathrm{MVO}_{2}$, cardiac oxygen consumption; $* p<0.05$ vs. $0 \mathrm{~min}, * * p<0.05$ vs. $30 \mathrm{~min}$

\section{Discussions}

Beta-blockers are well known for their efficacy in HF, but their use in the acute phase of HF is limited due to the risk of circulatory collapse. As a first step to safely administer $\beta$-blockers for cardioprotection in the acute phase of HF, we have developed and evaluated the feasibility of an automated drug administration system. The system administered the ultra-short-acting beta-blocker, landiolol, to decrease $\mathrm{MVO}_{2}$ while controlling mean AP and mean $\mathrm{P}_{\mathrm{LA}}$ to preset target values in a canine model of HF. It is the first system that automatically adjusts $\beta$-blockers to achieve cardioprotection while maintaining hemodynamics. In order to validate the utility and efficacy of the system for acute cardiovascular care, further studies with large sample sizes and development of clinically applicable system are needed.

The system controls the infusion of landiolol and dextran as well as injection of furosemide based on negative feedback control of hemodynamics. Mean AP and mean $\mathrm{P}_{\mathrm{LA}}$ reached the preset target values within $15 \mathrm{~min}$ after the system was activated. During the duration of hemodynamic control by the system, although AP decreased from

baseline, mean AP and systolic AP were maintained higher than 70 and $100 \mathrm{mmHg}$, respectively. Furthermore, the system decreased $\mathrm{HR}, \mathrm{P}_{\mathrm{LA}}$ and $\mathrm{MVO}_{2}$ significantly. Although the system reduced CO significantly, it did not alter lactate level. Therefore, our system administered landiolol and reduced $\mathrm{MVO}_{2}$ without inducing circulatory collapse under acute HF condition. In this study, we proved the concept of an automated drug administration system and evaluated its feasibility. Further studies are needed to demonstrate the superiority of this concept over existing therapies and its long-term prognostic effect.

\subsection{Comparison to other automated drug delivery systems}

Recently, various automated drug delivery systems have been developed in the field of anaesthesia [21-23] and for the control of volume status [24], AP [25-27] and HR [19]. Especially, the development of automated anaesthesia systems is progressing; for example, closed-loop feedback control of the bispectral index for stable control of hypnosis. Several meta-analyses have shown that automated 
Table 1 Performance of the automated drug control system

\begin{tabular}{|c|c|c|c|c|c|}
\hline \multicolumn{6}{|l|}{$\mathrm{AP}(\mathrm{mmHg})$} \\
\hline Animal number & $\begin{array}{l}\text { Time in acceptable } \\
\text { range }^{\text {a }}(\%)\end{array}$ & MDAPE $(\%)$ & MDPE (\%) & Wobble (\%) & Divergence $\left(\% \min ^{-1}\right)$ \\
\hline 1 & 100 & 3.8 & 3.7 & 3.7 & -0.25 \\
\hline 2 & 100 & 9.4 & 9.4 & 1.7 & -0.11 \\
\hline 3 & 100 & 1.5 & -1.1 & 2.5 & -0.05 \\
\hline 4 & 100 & 2.1 & -2.1 & 1.0 & -0.1 \\
\hline 5 & 100 & 3.7 & 3.7 & 2.6 & -0.14 \\
\hline \multirow[t]{2}{*}{6} & 100 & 2.5 & 2.5 & 1.6 & -0.08 \\
\hline & $100(100-100)$ & $3.1(2.2-3.8)$ & $3.1(-0.2-3.7)$ & $2.1(1.6-2.5)$ & $-0.1(-0.12-0.05)$ \\
\hline \multicolumn{6}{|l|}{$\mathrm{P}_{\mathrm{LA}}(\mathrm{mmHg})$} \\
\hline Animal number & $\begin{array}{l}\text { Time in acceptable } \\
\text { range }^{\text {b }}(\%)\end{array}$ & MDAPE (\%) & MDPE (\%) & Wobble (\%) & Divergence $\left(\% \cdot \mathrm{min}^{-1}\right)$ \\
\hline 1 & 99 & 3.2 & -2.2 & 3.0 & -0.24 \\
\hline 2 & 100 & 6.5 & -6.5 & 1.7 & 0.18 \\
\hline 3 & 92 & 1.8 & 0.5 & 2.5 & -0.004 \\
\hline 4 & 100 & 1.5 & -1.5 & 1.0 & -0.003 \\
\hline 5 & 81 & 6.2 & 2.6 & 2.6 & -0.5 \\
\hline \multirow[t]{2}{*}{6} & 100 & 4.1 & -4.1 & 1.6 & 0.03 \\
\hline & 99.7 (94-100) & $6.5(2.2-5.6)$ & $-1.8(-3.6-0.03)$ & $2.4(1.1-3.0)$ & $-0.003(-0.18-0.02)$ \\
\hline
\end{tabular}

Bottom rows show median (interquartile range) of 6 dogs

$A P$ arterial pressure, $M D A P E$ median absolute performance error, $M D P E$ median performance error, $P_{L A}$ left atrial pressure

${ }^{a}$ Mean AP within $5 \mathrm{mmHg}$ below target

${ }^{b}$ Mean $\mathrm{P}_{\mathrm{LA}}$ within $2 \mathrm{~mm}$ above target

Table 2 Results of blood gas analysis of six dogs

\begin{tabular}{lclccclc}
\hline & 0 min & \multicolumn{3}{c}{$30 \mathrm{~min}$} & $60 \mathrm{~min}$ & $\mathrm{p}$-value \\
\hline $\mathrm{pH}$ & 7.45 & $(7.42-7.46)$ & 7.45 & $(7.43-7.46)$ & 7.45 & $(7.41-7.45)$ & 0.68 \\
$\mathrm{PaO}_{2}(\mathrm{mmHg})$ & 99 & $(94-125)$ & 86 & $(72-118)$ & 107 & $(84-118)$ & 0.61 \\
$\mathrm{PaCO}_{2}(\mathrm{mmHg})$ & 28.4 & $(26.5-29.3)$ & 27.5 & $(26.6-28.5)$ & 28 & $(27.2-29.2)$ & 0.88 \\
$\mathrm{HCO}_{3}^{-}\left(\mathrm{mmol} \mathrm{l}^{-1}\right)$ & 18.5 & $(18.2-18.8)$ & 18.6 & $(18.2-18.6)$ & 18.4 & $(18.2-18.7)$ & 0.88 \\
$\mathrm{BE}\left(\mathrm{mmol} \mathrm{l}^{-1}\right)$ & -4.7 & $(-5.4$ to -3.8$)$ & -4.6 & $(-5.4$ to -4.1$)$ & -4.7 & $(-5.4$ to -4.4$)$ & 0.69 \\
Lactate $\left(\mathrm{mg} \mathrm{dl}^{-1}\right)$ & 11 & $(9-15)$ & 13 & $(10-16)$ & 13 & $(9-15)$ & 0.68
\end{tabular}

Data are expressed as median (interquartile range). $0 \mathrm{~min}, 30 \mathrm{~min}$, and $60 \mathrm{~min}$ represent the time after activating the automated drug delivery system

$\mathrm{PaO}_{2}$ partial pressure of arterial oxygen, $\mathrm{PaCO}_{2}$, partial pressure of arterial carbon dioxide, $\mathrm{BE}$ base excess anaesthesia delivery can be more effective than manually controlled anaesthesia by anaesthesiologists in attaining tight control with a specified range of target variables [28-30]. These systems also succeed to reduce the doses of anaesthetics delivered and shorten the recovery time. Regarding the use of $\beta$-blockers, Jannet et al. [19] proposed a closed-loop control system for esmolol infusion. They designed the system to control the infusion rate of esmolol so as to bring the ventricular rate to preset target value in dogs with induced atrial fibrillation. Negative feedback control of esmolol infusion rate stably controlled the ventricular rate. However, since they did not consider other hemodynamic parameters, $\mathrm{AP}$ and $\mathrm{P}_{\mathrm{LA}}$ during esmolol infusion could not be predicted or controlled.

To control AP and $\mathrm{P}_{\mathrm{LA}}$ during landiolol infusion, we designed the present system by extending our previous automated drug delivery systems based on the circulatory equilibrium framework [16-18]. In this framework, circulatory equilibrium $\left(\mathrm{CO}, \mathrm{P}_{\mathrm{LA}}\right.$, and $\left.\mathrm{P}_{\mathrm{RA}}\right)$ is determined by the intersection of the Frank-Starling curves and the venous return surface [31-33]. By controlling the Frank-Starling curves with dobutamine and the venous return surface with dextran 
and furosemide, the previous systems control $\mathrm{CO}, \mathrm{P}_{\mathrm{LA}}$, and $\mathrm{P}_{\mathrm{RA}}$ to desired values. Based on the same framework but with different logic, the present system controls the FrankStarling curves with landiolol and the venous return surface with dextran or furosemide to bring mean AP and mean $\mathrm{P}_{\mathrm{LA}}$ to pre-set target values (see Supplemental Material). In the canine HF model, the system automatically controlled mean AP and mean $\mathrm{P}_{\mathrm{LA}}$. Percent time in acceptable range for both $\mathrm{AP}$ and $\mathrm{P}_{\mathrm{LA}}$ was high, similar to previous reports for other closed-loop control systems [20, 23], indicating that the system avoided circulatory collapse (low AP and/or high $\mathrm{P}_{\mathrm{LA}}$ ). Furthermore, the control performance indices (MDPE, MDAPE, wobble, and divergence) were small, comparable to those observed in previous reports of closed-loop hemodynamic control systems [26, 34]. These results suggest that our system using $\beta$-blockers achieves the same degree of hemodynamic control as previously reported closed-loop systems.

Regarding the control speed, the system stabilized the hemodynamics within $15 \mathrm{~min}$. This is considerably shorter than the clinical time required for dose titration of landiolol (more than $30 \mathrm{~min}$ ) [14]. Therefore, the present system is the first system that achieves automated control of hemodynamics using $\beta$-blockers while decreasing $\mathrm{MVO}_{2}$ in dogs with HF.

\subsection{Acute hemodynamic effects of the system}

We designed the present system to infuse a maximum dose of landiolol in individual subject, since the benefit of $\beta$-blockers depends on the dosage. In anaesthetized dogs, Satoh et al. [35] reported that $\beta$-blockers dose-dependently reduced $\mathrm{AP}, \mathrm{HR}$ and $\mathrm{MVO}_{2}$.

However, a high dose of $\beta$-blocker suppresses cardiac pumping function, especially under HF conditions. Indeed, infusion of landiolol by our system decreased AP and CO. Although there is no clear clinical evidence of acceptable AP range under acute HF condition, previous studies recommended to maintain mean AP of over $65 \mathrm{mmHg}$ in cardiogenic shock [36] or following septic shock [37]. Therefore, we set $\mathrm{AP}^{*}$ as $10-15 \mathrm{mmHg}$ lower than mean baseline AP, but not lower than $70 \mathrm{mmHg}$. During hemodynamic control by our system, mean AP decreased from $87 \mathrm{mmHg}$ (85-89) at baseline to $77 \mathrm{mmHg}(73-81)$ at $60 \mathrm{~min}$, and the minimum AP was $70 \mathrm{mmHg}$. Previous clinical studies evaluating the efficacy of landiolol to treat atrial fibrillation or ventricular tachy-arrhythmia in acute HF have indicated that landiolol induces hypotension in $7.5-20 \%$ of HF patients $[14,15]$. On the other hand, although systolic AP was not a controlled variable in our system, it was maintained at not lower than $100 \mathrm{mmHg}$ in all animals in this study. Hence, our system did not induce critical hypotension and achieved safe control of hemodynamics using $\beta$-blocker. Regarding
$\mathrm{CO}$, Cooper et al. [38] reported that $\mathrm{CO}$ observed after acute phase treatment in patients with acute decompensated HF was not associated with mortality or cardiovascular hospitalisation, whereas pulmonary capillary wedge pressure was a strong predictor of these events. Therefore, we designed the system to control AP and $\mathrm{P}_{\mathrm{LA}}$, but not $\mathrm{CO}$. Although $\mathrm{CO}$ decreased from $118 \mathrm{ml} \mathrm{min}{ }^{-1} \mathrm{~kg}^{-1}(101-124)$ at baseline to $84 \mathrm{ml} \mathrm{min}^{-1} \mathrm{~kg}^{-1}$ (64-95) at $60 \mathrm{~min}$, blood lactate level remained unaltered. This result suggests that the decrease of CO (approximately 30\% reduction) when using the system may not reach a critical level. Another possibility is that landiolol may reduce peripheral oxygen consumption, thereby improving the oxygen demand-supply balance. Indeed, several previous results suggest that $\beta$-blockers suppress systemic oxygen utilisation or renal oxygen consumption $[39,40]$. However, the post hoc power analysis showed low statistical power for blood lactate level, indicating that the sample size $(n=6)$ was not large enough to conclude that blood lactate level was not elevated. In addition, blood lactate level alone is not sufficient to assess the damage to peripheral organs (including brain, kidney, and liver). Biomarkers such as serum creatinine, cystatin $\mathrm{C}$, and hepatic transaminases need to be evaluated. However, hemodynamic control was tested for only $60 \mathrm{~min}$ in this study, which was not long enough to evaluate such biomarkers. Further studies with larger sample size and more detailed evaluation of organ damage are needed.

\subsection{Clinical application of our system}

Since we invasively measured CO, $\mathrm{P}_{\mathrm{RA}}$ and $\mathrm{P}_{\mathrm{LA}}$ in this study, the present experimental setting may not apply directly to clinical practice. In the clinical setting, pulmonary artery catheterization (PAC) allows measurements of continuous thermodilution $\mathrm{CO}$, central venous pressure, and diastolic pulmonary arterial pressure. By estimating $\mathrm{P}_{\mathrm{LA}}$ from diastolic pulmonary arterial pressure, the system can be applied clinically. However, PAC is invasive and sampling for continuous thermodilution $\mathrm{CO}$ requires one minute. Thus, we have proposed less invasive monitoring methods for $\mathrm{CO}$ and $\mathrm{P}_{\mathrm{LA}}$ using the ultrasound technique [17, 41, 42]. In brief, CO is estimated by left ventricular outflow tract velocity time integral and AP. $\mathrm{P}_{\mathrm{RA}}$ is substituted by the jugular vein pressure $\left(\mathrm{P}_{\mathrm{JV}}\right) . \mathrm{P}_{\mathrm{LA}}$ is estimated from the velocity of mitral and tricuspid annulus and $\mathrm{P}_{\mathrm{JV}}$. These monitoring methods may be selected based on the needs for PAC. The use of these monitoring methods should be explored to further develop the present system for clinical application.

\subsection{Limitations}

The limitations of this study have to be addressed. First, the sample size was small. The low statistical power shown in 
the post hoc power analysis (Table S1, Supplemental material) indicated that the sample size $(n=6)$ was not large enough to rule out type 2 error in several variables. Second, all animals were anesthetized and ventilated. Anaesthesia and ventilation are known to affect hemodynamics [43]. The results of this study may be different under awake conditions. However, we consider that the negative feedback mechanism used in the present system may compensate for the variations in drug responses between anesthetized and awake states. Third, we only assessed acute $\mathrm{MVO}_{2}$ change. Further studies are needed to elucidate whether the improved myocardial energetics achieved by the present system ameliorates myocardial damage and improves long-term survival in HF subjects. Fourth, we used a rapid pacing-induced HF model. It is well known that the cardiac function in this model improves spontaneously once rapid pacing is stopped [44]. To observe whether cardiac function improved spontaneously, we monitored hemodynamics in three of six dogs for 120 min after the end of hemodynamic control (Table S2 in Supplemental material). In these three dogs, we observed no systematic improvement of hemodynamics. These results may imply that cardiac function did not recover spontaneously during 60 min of hemodynamic control. However, a control group without $\beta$-blocker administration is required to exclude the effect of spontaneous cardiac recovery for accurate interpretation of the results. Finally, no comparison was made with conventional use of landiolol. Further studies are needed to compare with fixed landiolol or manual control of landiolol to demonstrate its superiority over current treatments.

\section{Conclusions}

We have developed and evaluated the feasibility Queryof an automated drug delivery system that adjusts the infusion rate of landiolol to reduce $\mathrm{MVO}_{2}$ without inducing circulatory collapse. In a canine model of HF, this system significantly reduced $\mathrm{MVO}_{2}$ indicating the potential of cardioprotection. The system controlled both mean AP and mean $\mathrm{P}_{\mathrm{LA}}$ within the acceptable control ranges more than $95 \%$ of the time, and MDPAE for AP and $\mathrm{P}_{\mathrm{LA}}$ was less than $10 \%$. These results indicate that the system may improve cardiac energetics and reduce myocardial damage in acute HF. This study is the first step to develop a method of safe administration of $\beta$-blockers for cardioprotection in the acute phase of HF. To establish this system for clinical use, further validation studies with large sample sizes and development for clinical applicable system are needed.

Supplementary Information The online version contains supplementary material available at https://doi.org/10.1007/s10877-021-00717-w.
Acknowledgements The authors thank the staff of the Department of Cardiovascular Dynamics, National Cerebral and Cardiovascular Center.

Author contributions $\mathrm{TN}$ and $\mathrm{KU}$ designed the study. TN wrote the initial draft of the manuscript. TN and KU performed the experiments. $\mathrm{TN}, \mathrm{KU}, \mathrm{YH}$ and MS contributed to analysis and interpretation of the data, and assisted in preparation of the manuscript. TN, KU, KS, TK, and MS contributed to interpretation of data, and critically reviewed the manuscript. All authors read and approved the final version of the manuscript, and agreed to be accountable for all aspects of the work in ensuring that questions related to the accuracy or integrity of any part of the work are appropriately investigated and resolved.

Funding This work was supported by Intramural Research Fund (31-64) for Cardiovascular Diseases of National Cerebral and Cardiovascular Center, Early-Career Scientists (19K20690) from the Japan Society for the Promotion of Science, Grant-in-Aid for Scientific Research (C) (18K12126) from the Japan Society for the Promotion of Science.

Data availability The datasets used and/or analysed during this study are available from the corresponding author on reasonable request.

Code availability The code used in this study are available from the corresponding author on reasonable request.

\section{Declarations}

Conflict of interest KS received research funding from Omron Healthcare Co., Ltd., Abiomed Japan K.K., and Zeon Medical Inc., and honoraria from Abiomed Japan K.K. KU received research funding from A\&D Co., Ltd.

Ethical approval Animal care was performed in strict accordance with the Guiding Principles for Care and Use of Animals in the Field of Physiological Sciences, which has been approved by the Physiological Society of Japan. All experiments in this study were approved by the Animal Subjects Committee at the National Cerebral and Cardiovascular Center.

Open Access This article is licensed under a Creative Commons Attribution 4.0 International License, which permits use, sharing, adaptation, distribution and reproduction in any medium or format, as long as you give appropriate credit to the original author(s) and the source, provide a link to the Creative Commons licence, and indicate if changes were made. The images or other third party material in this article are included in the article's Creative Commons licence, unless indicated otherwise in a credit line to the material. If material is not included in the article's Creative Commons licence and your intended use is not permitted by statutory regulation or exceeds the permitted use, you will need to obtain permission directly from the copyright holder. To view a copy of this licence, visit http://creativecommons.org/licenses/by/4.0/.

\section{References}

1. Aurbach GD, Spiegel AM, Gardner JD. Beta-adrenergic receptors, cyclic AMP, and ion transport in the avian erythrocyte. Adv Cyclic Nucleotide Res. 1975;5:117-32 (Internet).

2. Jorgensen CR, Wang K, Wang Y, Gobel FL, Nelson RR, Taylor $\mathrm{H}$. Effect of propranolol on myocardial oxygen consumption and 
its hemodynamic correlates during upright exercise. Circulation. 1973;48:1173-82 (Internet).

3. Al-Hesayen A, Azevedo ER, Floras JS, Hollingshead S, Lopaschuk GD, Parker JD. Selective versus nonselective beta-adrenergic receptor blockade in chronic heart failure: differential effects on myocardial energy substrate utilization. Eur J Heart Fail. 2005;7:618-23 (Internet)

4. Fung JWH, Yu CM, Yip G, Chan S, Yandle TG, Richards AM, et al. Effect of beta blockade (carvedilol or metoprolol) on activation of the renin-angiotensin-aldosterone system and natriuretic peptides in chronic heart failure. Am J Cardiol. 2003;92:406-10 (Internet).

5. Nakamura K, Murakami M, Miura D, Yunoki K, Enko K, Tanaka $\mathrm{M}$, et al. Beta-blockers and oxidative stress in patients with heart failure. Pharmaceuticals (Basel). 2011;4:1088-100 (Internet).

6. Sakanashi M, Sakanashi M, Sugahara K, Sakanashi M. Effects of landiolol on mechanical and metabolic changes in rat reperfused ischaemic hearts. Clin Exp Pharmacol Physiol. 2007;34:55-60 (Internet)

7. Packer M, Bristow MR, Cohn JN, Colucci WS, Fowler MB, Gilbert EM, U.S. Carvedilol Heart Failure Study Group, et al. The effect of carvedilol on morbidity and mortality in patients with chronic heart failure. N Engl J Med. 1996;334:1349-55 (Internet).

8. Committees C-I investigators. The cardiac insufficiency bisoprolol study II (CIBIS-II): a randomised trial. Lancet (London, England). 1999;353:9-13 (Internet).

9. Butler MJ, Britton BJ, Wood WG, Mainwaring-Burton R, Irving $\mathrm{MH}$. Plasma catecholamine concentrations during operation. $\mathrm{Br}$ J Surg. 1977;64:786-90 (Internet).

10. Varon J, Marik PE. Perioperative hypertension management. Vasc Health Risk Manag. 2008;4:615-27.

11. Sousa-Uva M, Head SJ, Milojevic M, Collet J-P, Landoni G, Castella M, et al. 2017 EACTS guidelines on perioperative medication in adult cardiac surgery. Eur J Cardiothorac Surg. 2018;53:533 (Internet).

12. Prins KW, Neill JM, Tyler JO, Eckman PM, Duval S. Effects of beta-blocker withdrawal in acute decompensated heart failure. A systematic review and meta-analysis. JACC Heart Fail. 2015;3:647-53 (Internet).

13. Lund-Johansen P, Omvik P. Acute and chronic hemodynamic effects of drugs with different actions on adrenergic receptors: a comparison between alpha blockers and different types of beta blockers with and without vasodilating effect. Cardiovasc Drugs Ther. 1991;5:605-15 (Internet).

14. Nagai R, Kinugawa K, Inoue H, Atarashi H, Seino Y, Yamashita $\mathrm{T}$, et al. Urgent management of rapid heart rate in patients with atrial fibrillation/flutter and left ventricular dysfunction: comparison of the ultra-short-acting $\beta 1$-selective blocker landiolol with digoxin (J-Land study). Circ J. 2013;77:908-16 (Internet).

15. Ikeda T, Shiga T, Shimizu W, Kinugawa K, Sakamoto A, Nagai $\mathrm{R}$, et al. Efficacy and safety of the ultra-short-acting $\beta 1$-selective blocker landiolol in patients with recurrent hemodynamically unstable ventricular tachyarrhymias-outcomes of J-Land II study. Circ J. 2019;83:1456-62 (Internet).

16. Uemura K, Kamiya A, Hidaka I, Kawada T, Shimizu S, Shishido $\mathrm{T}$, et al. Automated drug delivery system to control systemic arterial pressure, cardiac output, and left heart filling pressure in acute decompensated heart failure. J Appl Physiol. 2006;100:1278-86 (Internet).

17. Uemura K, Kawada T, Zheng C, Sugimachi M. Less invasive and inotrope-reduction approach to automated closed-loop control of hemodynamics in decompensated heart failure. IEEE Trans Biomed Eng. 2016;63:1699-708 (Internet).

18. Uemura K, Kawada T, Zheng C, Li M, Sugimachi M. Computercontrolled closed-loop drug infusion system for automated hemodynamic resuscitation in endotoxin-induced shock. BMC Anesthesiol. 2017; 17:145 (Internet).

19. Jannett TC, Kay GN, Crossley GH. Modeling and closed-loop pharmacologic control of the ventricular rate during induced atrial fibrillation in anesthetized dogs. Biomed Instrum Technol. 1990;24:445-50 (Internet).

20. Ngan Kee WD, Khaw KS, Ng FF, Tam YH. Randomized comparison of closed-loop feedback computer-controlled with manual-controlled infusion of phenylephrine for maintaining arterial pressure during spinal anaesthesia for caesarean delivery. Br J Anaesth. 2013;110:59-65.

21. LE Guen M, Liu N, Chazot T, Fischler M. Closed-loop anesthesia. Minerva Anestesiol. 2016;82:573-81 (Internet).

22. Liu Y, Li M, Yang D, Zhang X, Wu A, Yao S, et al. Closed-loop control better than open-loop control of profofol TCI guided by BIS: a randomized, controlled, multicenter clinical trial to evaluate the CONCERT-CL closed-loop system. PLoS ONE. 2015; 10:e0123862 (Internet).

23. Luginbühl M, Bieniok C, Leibundgut D, Wymann R, Gentilini A, Schnider TW. Closed-loop control of mean arterial blood pressure during surgery with alfentanil: clinical evaluation of a novel model-based predictive controller. Anesthesiology. 2006;105:462-70 (Internet).

24. Biegus J, Zymlinski R, Siwolowski P, Testani J, Szachniewicz J, Tycińska A, et al. Controlled decongestion by reprieve therapy in acute heart failure: results of the TARGET-1 and TARGET-2 studies. Eur J Heart Fail. 2019;21:1079-87 (Internet).

25. Soltesz K, Sjöberg T, Jansson T, Johansson R, Robertsson A, Paskevicius A, et al. Closed-loop regulation of arterial pressure after acute brain death. J Clin Monit Comput. 2018;32:429-37 (Internet).

26. Kee WDN, Tam Y-HH, Khaw KS, Ng FF, Lee SWYY. Closedloop feedback computer-controlled phenylephrine for maintenance of blood pressure during spinal anesthesia for cesarean delivery: a randomized trial comparing automated boluses versus infusion. Anesth Analg. 2017;125:117-23 (Internet).

27. Joosten A, Delaporte A, Alexander B, Su F, Creteur J, Vincent $\mathrm{JL}$, et al. Automated titration of vasopressor infusion using a closed-loop controller: in vivo feasibility study using a swine model. Anesthesiology. 2019;130:394-403.

28. Brogi E, Cyr S, Kazan R, Giunta F, Hemmerling TM. Clinical performance and safety of closed-loop systems: a systematic review and meta-analysis of randomized controlled trials. Anesth Analg. 2017;124:446-55 (Internet).

29. Pasin L, Nardelli P, Pintaudi M, Greco M, Zambon M, Cabrini $\mathrm{L}$, et al. Closed-loop delivery systems versus manually controlled administration of total IV anesthesia: a meta-analysis of randomized clinical trials. Anesth Analg. 2017;124:456-64 (Internet).

30. Puri GD, Mathew PJ, Biswas I, Dutta A, Sood J, Gombar S, et al. A multicenter evaluation of a closed-loop anesthesia delivery system: a randomized controlled trial. Anesth Analg. 2016;122:10614 (Internet).

31. Guyton AC. Determination of cardiac output by equating venous return curves with cardiac response curves. Physiol Rev. 1955;35:123-9 (Internet)

32. Sunagawa K, Sagawa K, Maughan WL. Ventricular interaction with the loading system. Ann Biomed Eng. 1984;12:163-89 (Internet).

33. Uemura K, Sugimachi M, Kawada T, Kamiya A, Jin Y, Kashihara $\mathrm{K}$, et al. A novel framework of circulatory equilibrium. Am J Physiol Heart Circ Physiol. 2004;286:H2376-85 (Internet).

34. Sng BL, Wang H, Assam PN, Sia AT. Assessment of an updated double-vasopressor automated system using $\mathrm{Nexfin}^{\mathrm{TM}}$ for the maintenance of haemodynamic stability to improve peri-operative 
outcome during spinal anaesthesia for caesarean section. Anaesthesia. 2015;70:691-8.

35. Satoh N, Suzuki J, Bessho H, Kitada Y, Narimatsu A, Tobe A. Effects of betaxolol on cardiohemodynamics and coronary circulation in anesthetized dogs: comparison with atenolol and propranolol. Jpn J Pharmacol. 1990;54:113-9 (Internet).

36. Vahdatpour C, Collins D, Goldberg S. Cardiogenic shock. J Am Heart Assoc. 2019;8:e011991 (Internet).

37. Varpula M, Tallgren M, Saukkonen K, Voipio-Pulkki L-M, Pettilä V. Hemodynamic variables related to outcome in septic shock. Intensive Care Med. 2005;31:1066-71 (Internet).

38. Cooper LB, Mentz RJ, Stevens SR, Felker GM, Lombardi C, Metra M, et al. Hemodynamic predictors of heart failure morbidity and mortality: fluid or flow? J Card Fail. 2016;22:182-9 (Internet).

39. Podbregar M, Voga G. Effect of selective and nonselective $\beta$-blockers on resting energy production rate and total body substrate utilization in chronic heart failure. J Card Fail. 2002;8:369-78.

40. Hall ME, Rocco MV, Morgan TM, Hamilton CA, Jordan JH, Edwards MS, et al. Beta-blocker use is associated with higher renal tissue oxygenation in hypertensive patients suspected of renal artery stenosis. CardioRenal Med. 2016;6:261-8.
41. Uemura K, Inagaki M, Zheng C, Li M, Kawada T, Sugimachi M. A novel technique to predict pulmonary capillary wedge pressure utilizing central venous pressure and tissue Doppler tricuspid/mitral annular velocities. Heart Vessel. 2015;30:516-26 (Internet).

42. Uemura K, Kawada T, Inagaki M, Sugimachi M. A minimally invasive monitoring system of cardiac output using aortic flow velocity and peripheral arterial pressure profile. Anesth Analg. 2013;116:1006-17 (Internet).

43. Beam DM, Neto-Neves EM, Stubblefield WB, Alves NJ, Tune JD, Kline JA. Comparison of isoflurane and $\alpha$-chloralose in an anesthetized swine model of acute pulmonary embolism producing right ventricular dysfunction. Comp Med. 2015;65:54-61 (Internet).

44. Moe GW, Stopps TP, Howard RJ, Armstrong PW. Early recovery from heart failure: insights into the pathogenesis of experimental chronic pacing-induced heart failure. J Lab Clin Med. 1988;112:426-32 (Internet).

Publisher's Note Springer Nature remains neutral with regard to jurisdictional claims in published maps and institutional affiliations. 